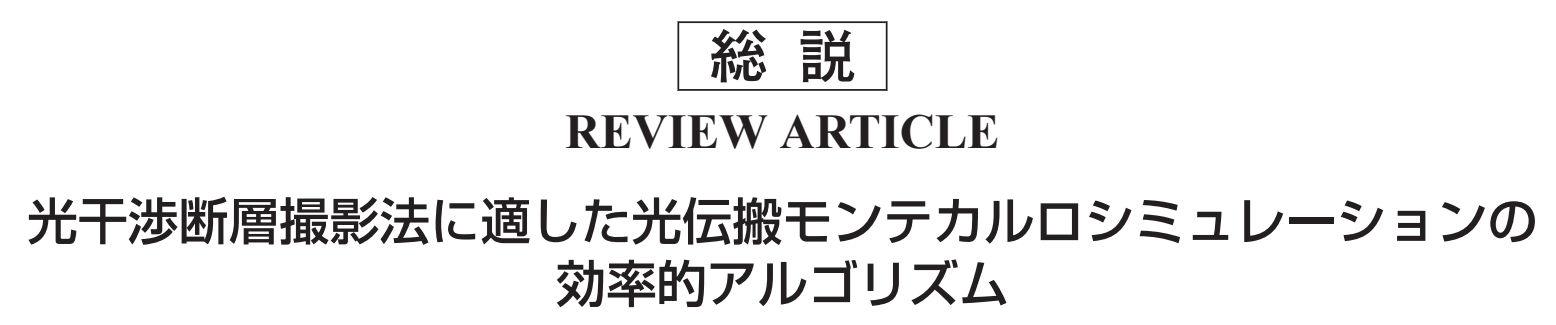

石井 勝弘

光産業創成大学院大学 光情報・システム分野

( 2018 年 10 月 15 日受付， 2018 年 12 月 2 日掲載決定， 2019 年 5 月 23 日 J-STAGE 早期公開)

\title{
Efficient Algorithm of Monte-Carlo Simulation of Light Propagation for Optical Coherence Tomography
}

Katsuhiro Ishii

The Graduate School for the Creation of New Photonics Industries

(Received October 15, 2018, Accepted December 2, 2018, Advance Publication released online May 23, 2019)

\section{要 旨}

入射光と同じ位置から出射する特定の長さの光路長の散乱光のみを効率的に解析することができるモンテカルロ法 について解説する。均一な散乱媒質と散乱特性に空間分布がある散乱媒質に対するこのモンテカルロ法の適用方法を 説明し，解析例を示す。このシミュレーションは光干渉断層撮影法で検出される散乱光の解析を効率的に行うことが できる。

キーワード : モンテカルロ法，光散乱，光路長分布，輸送方程式，光干渉断層撮影法

\begin{abstract}
Efficient algorithm of Monte-Carlo simulation of scattered light which re-emerges from the incident point of light and has a specific pathlength is reviewed. Calculation procedures of this algorithm for uniform and nonuniform scattering media are explained and examples of simulation results are shown. This algorithm can efficiently analyze scattered light detected by optical coherence tomography.
\end{abstract}

Key words: Monte Carlo simulation, light scattering, pathlength distribution, radiative transfer equation, optical coherence tomography

\section{1. はじめに}

光計測技術と計測機器の進展により光を用いて生体内 部を可視化する生体光計測は大きく発展しており，さま ざまな臨床診断への取り組みが行われている ${ }^{1,2)}$. 生体は 光に対して強い散乱体であり, 生体光計測において散乱 は重要な問題である。生体からの多重散乱光（拡散光） を利用して生体内部を可視化する技術が拡散光トモグラ フィー3)，および，光トポグラフィー4)である。前者は
乳がんの診断装置 5)として欧米で実用化されつつあり， 後者は脳表面の血中酸素飽和度をイメージングする装置 であり，うつ病や統合失調症などの精神疾患の診断に利 用されている6)。一方，多重散乱光の影響を抑え準直進 光のみを検出することで生体内部を可視化する技術が光 干渉断層撮影法であり，眼底における網膜剥離の診断装 置として普及している ${ }^{7,8)}$.

生体光計測では，光計測技術と計測機器の進展と同時

干 431-1202 静岡県浜松市西区只松町 1955-1 TEL: 053-484-2648, FAX: 053-487-3012

(1955-1, Kurematsu-cho, Nishi-ku, Hamamatsu, Shizuoka 431-1202, Japan)

Corresponding author: ishii@gpi.ac.jp (石井勝弘) 
に，光計測で取得される信号から散乱体内部の情報を推 定するための散乱光の光伝搬解析が重要である. 生体内 部の光伝搬は，輸送方程式によって表すことができ る ${ }^{9,10)}$. 輸送方程式を解析的に解くことは難しい. 光が十 分に多重散乱され光の伝搬がほぼ等方的 (拡散的)になっ ている場合は，光伝搬は拡散方程式に従うと近似するこ とができる。これは拡散近似と呼ばれる。拡散方程式は 解析解を求めることができ，半無限空間に広がる散乱体 の一点にパルス光を照射したときの散乱光の時間波形や 空間分布が得られる. また，有限要素法などを用いて数 值解を求めることもできる. これらの解析は，拡散光卜 モグラフィーや，光トポグラフィーにおいて利用されて いる. しかし，拡散近似は，入射点近傍の空間分布や， 早い領域の時間応答など, 光が拡散的になる前の光の伝 搬を正確に表すことはできない。

輸送方程式の解を統計的に求める方法がモンテカルロ 法である ${ }^{11)}$. モンテカルロ法の解析は, 散乱体内部の散 乱を乱数により発生させ，光の伝搬経路を決定する. 非 常に多数の伝搬経路を発生させることで，統計的に，光 の伝搬を解くことができる，モンテカルロ法は近似解で はないため, 拡散近似のような制限はなく, すべての領 域の光伝搬を表すことが可能であり, 準直進光の解析に も利用することができる. モンテカルロ法では, 散乱光 の光路長 (伝搬時間) や出射位置は, 実際の確率に従っ てランダムに決まる. 多数の経路を発生させることで統 計的に光路長分布や出射位置が決定される. 一方，特定 の出射位置 (検出位置) からの光, さらには, 特定の光 路長の光のみを解析しようとする場合には，興味のある 伝搬経路は，発生させた多数の伝搬経路のごく一部とな り, 計算効率が低い. しかし, 現在の計算機の能力を用 いれば，これらの解析も可能ではある.

筆者らは，光干渉断層撮影法と同じ低コヒーレンス干 渉計を用いて高濃度粒子溶液の粒子径計測を行う低コ ヒーレンス動的光散乱計測法の研究のなかで, 入射点と 同じ位置から出射する特定の光路長の伝搬経路のみを発 生させるモンテカルロ法のアルゴリズムを提案した ${ }^{12)}$. さらに, 光干渉断層撮影法への応用を考え, このモン テカルロ法を散乱媒質内部の伝搬解析へと展開してい る13,14). 本解説では，特定の光路長の伝搬経路のみを発 生させるモンテカルロ法のアルゴリズムと，それを用い た散乱媒質内部の伝搬解析について述べる.

\section{2. 輸送方程式とモンテカルロ法}

散乱体内の光の伝搬は，光のエネルギーの流れを表す 輸送方程式で表すことができる ${ }^{9)}$. 位置 $\mathbf{r}$ での $\widehat{\mathbf{s}}$ 方向へ 伝搬する単位面積，単位立体角，単位時間当たりの光の エネルギー (光強度) $I(\mathbf{r}, \widehat{\mathbf{s}})$ を用いると, 輸送方程式は

$$
\begin{aligned}
& \frac{d I(\mathbf{r}, \widehat{\mathbf{s}})}{d s} \\
& \quad=-\mu_{t} I(\mathbf{r}, \widehat{\mathbf{s}})+\mu_{s} \int_{4 \pi} p\left(\widehat{\mathbf{s}}, \widehat{\mathbf{s}}^{\prime}\right) I\left(\mathbf{r}, \widehat{\mathbf{s}}^{\prime}\right) d \omega^{\prime}+\varepsilon(\mathbf{r}, \widehat{\mathbf{s}})
\end{aligned}
$$

と表すことができる.ここで， $\mu_{t}, \mu_{s}, p\left(\widehat{\mathbf{s}}, \widehat{\mathbf{s}}^{\prime}\right), \omega$, およ び, $\varepsilon(\mathbf{r}, \widehat{\mathbf{s}})$ は, それぞれ, 減光係数, 散乱係数, 位相関 数, 立体角, 光源の光強度である.（1）式の輸送方程式
の左辺は，光の伝搬に伴う光強度の変化であり，右辺 1 項目は散乱と吸収による光強度の減衰，2 項目は $\widehat{\mathbf{s}}$ 方向 への散乱による光強度の増加，3 項目は光源による増加 をそれぞれ表している，光源がなく，散乱による光強度 の増加が無視できる場合には，右辺は 1 項目のみとなる. これはランバート・ベール則であり，この時. 光強度は, 伝搬とともに指数関数的に減衰する. 輸送方程式を解く 1 つの方法は, 強い散乱体では光の伝搬はほぼ等方的で あると仮定する拡散近似である。これについては参考文 献 9)と 10)を参照されたい.

輸送方程式は 1 階の線形微分方程式であり，その一般 解は

$$
I(\mathbf{r}, \widehat{\mathbf{s}})=C \mathrm{e}^{-\tau}+\int_{-\infty}^{s} Q\left(\mathbf{r}_{1}, \widehat{\mathbf{s}}\right) \mathrm{e}^{-\left(\tau-\tau_{1}\right)} d s_{1}
$$

となる.ここで, $C$ は定数, $\tau=\int_{-\infty}^{s} \mu_{t} d s$ と $\tau_{1}=\int_{-\infty}^{s_{1}} \mu_{t} d s_{1}$ は，それぞれ，位置 $\mathbf{r}$ と $\mathbf{r}_{1}$ までの光路長，

$$
Q(\mathbf{r}, \widehat{\mathbf{s}})=\mu_{s} \int_{4 \pi} p\left(\widehat{\mathbf{s}}, \widehat{\mathbf{s}}^{\prime}\right) I\left(\mathbf{r}, \widehat{\mathbf{s}}^{\prime}\right) d \omega^{\prime}+\varepsilon(\mathbf{r}, \widehat{\mathbf{s}})
$$

は，位置 $\mathbf{r}$ での $\widehat{\mathbf{s}}$ 方向への散乱と光源の強さを表してい る. (2) 式の右辺の 1 項目は, ランバート・ベール則に 従う項で，適当に境界条件を設定すれば，定数 $C$ が決定 できる. 2 項目は，散乱と光源による光の増加を表す項 であり，位置 $\mathbf{r}_{1}$ で散乱と光源により増加した光も，その 後はランバート・ベール則に従い，指数関数的に減衰す ることを示している。（2）式で示される輸送方程式の一 般解は光強度の分布を与える式ではあるが，右辺にも光 強度が入っているので，そこから光強度を求めることは 難しい. そこで, 光強度を散乱回数ごとに分けて考えて みると，(2) 式は

$$
\begin{aligned}
& I_{n}(\mathbf{r}, \widehat{\mathbf{s}}) \\
& \quad=\int_{-\infty}^{s}\left[\mu_{s} \int_{4 \pi} p\left(\widehat{\mathbf{s}}, \widehat{\mathbf{s}}^{\prime}\right) I_{n-1}\left(\mathbf{r}_{1}, \widehat{\mathbf{s}}^{\prime}\right) d \omega^{\prime}\right] e^{-\left(\tau-\tau_{1}\right)} d s_{1}
\end{aligned}
$$

となる。したがって, $(n-1)$ 回散乱の光強度がわかれ ば， $n$ 回散乱の光強度が計算できる。したがって，入射 光の光強度から, 1 回散乱, 2 回散乱と順番に光強度を計 算していけば，輸送方程式を解くことができる。これを 行っているのがモンテカルロ法である.

ここで，モンテカルロ積分について説明する．定積分 $\int_{a}^{b} f(x) d x$ を数值積分することを考える. この積分を数 值計算する 1 つの方法は，積分範囲内を $N$ 個 $\left(x_{1}, x_{2}, \ldots\right.$, $x_{N}$ ）に等分割し，それぞれの区間の面積（関数の值と 幅の積）を足し合わせることで, 以下の式より計算で きる。

$$
\int_{a}^{b} f(x) d x \cong \frac{b-a}{N} \sum_{i=1}^{N} f\left(x_{i}\right)
$$

モンテカルロ積分は，積分範囲の中から乱数を用いて $N$ 
個の点 $\left(\xi_{1}, \xi_{2}, \ldots, \xi_{N}\right)$ を選び，以下の式で定積分を計算 する.

$$
\int_{a}^{b} f(x) d x \cong \frac{1}{N} \sum_{i=1}^{N} \frac{f\left(\xi_{i}\right)}{g\left(\xi_{i}\right)}
$$

ここで, $g(x)$ は乱数の確率密度関数である. 一様乱数を 用いる場合，確率密度関数は $g(x)=1 /(b-a)$ であり，(6) 式と（5）式は同じ形である。一方, 確率密度関数 $g(x) \propto$ $f(x)$ が被積分関数に比例する乱数を用いる場合は, 総和の 中は定数となり, 被積分関数 $f(x)$ の值を評価する必要は なくなる. この時，積分への寄与が大きくなる被積分関 数 $f(x)$ が大きな值となるような $x$ がより多く選ばれ, 積 分への寄与が少ない $x$ の值はあまり選ばれなくなってい る.このような乱数を用いると, 積分の誤差が小さくなる. 光散乱のモンテカルロ法は, 次の手順で行われる。媒 質に入射された光は，散乱されるまで媒質内を直進する. この時, 入射光 (0 回散乱光) の光強度は (2) 式の右辺 1 項目で示されるように指数関数的に減衰する. 1 回目の 散乱点の位置は 0 回散乱光の強度に比例するので，その 強度分布に比例した確率密度関数を用いて散乱位置を決 定する. 散乱位置の決定は，取りえる光路長の範囲内の 一様乱数を発生させ，その光路長に対応した減衰を重及 とすることも可能である. しかし，この方法ではほとん ど発生しない長い光路長を多く発生させることになり, 精度が悪くなる. 次に, 散乱の位相関数に従う乱数を用 いて，散乱方向を決定する. これも一様乱数で散乱角を 決定し, その方向の散乱の強さを重みとすることも可能 である. 光が最初に散乱される点の位置とその点で散乱 された光が進む散乱方向を乱数を用いて決定し, 1 回散 乱の光強度を計算することは，(4) 式をモンテカルロ積 分で数值計算していることになる。 これを散乱光が媒質 から出射するまで繰り返すことで, 各散乱回数の光強度 を計算することができる. また, 各散乱回数の散乱位置, 出射光の出射位置, 散乱回数, 光路長等も評価すること ができる。

\section{3. 特定の光路長の伝搬経路のみを発生させるモンテカル} 口法

通常のモンテカルロ法による光散乱解析では, 散乱光 の出射位置と光路長（時間）はその発生確率に従ってラ ンダムに決定される。しかし，特定の検出位置での光路 長分布やパルス光を入射したときの時間波形を解析する 場合には, 対象となる散乱光の発生確率は低く, 計算効 率が悪い. 特定の位置から出射される特定の長さの光路 長をもつ伝搬経路のみをランダムに発生させることがで きると，計算効率が向上し，精度も高くなる。本章では， 文献 12)で提案されたモンテカルロ法について説明する. この方法は，光干渉断層撮影法と同じ低コヒーレンス干 渉計で計測される多重散乱光の光路長分布を解析するた めに導入された. Fig. 1 に示されるような, 散乱媒質に垂 直に入射され，特定の長さの光路を伝搬し，入射点と同 じ位置から垂直に出射する散乱光の伝搬経路のみを発生 させ，モンテカルロ積分を用いて光伝搬を解析する.こ の解析では, 各散乱回数ごとに出射光の光強度をそれぞ れモンテカルロ積分で計算する.

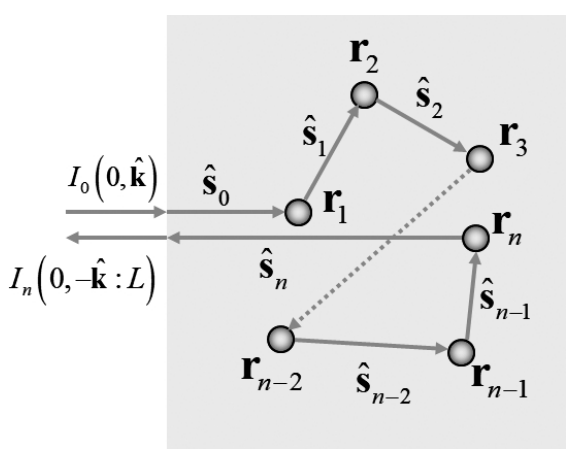

Fig.1 Configuration of scattering points and scattering processes in scattering medium. Light is normally incident on a scattering medium and re-emerges from the same point after propagation along path with pathlength of $L$ and $n$ times of scatterings.

直交座標系の $x y$ 平面を境界とし,$z>0$ の半無限空間 に存在する散乱媒質に, 原点から垂直に光強度 $I_{0}(0, \widehat{\mathbf{k}})$ の 光が入射され, 光路長 $L$ の光路を伝搬した後, 原点から 垂直に出射される $n$ 回散乱光の光強度 $I_{n}(0,-\widehat{\mathbf{k}} ; L)$ を考え る. 散乱媒質の散乱特性は均一である場合を考える.

初めに 1 回散乱光の光強度を考える. この場合, Fig.2(a) に示すように入射光軸上の深さ $L / 2$ の位置が散乱点であ り，そこで光は後方に散乱される。したがって，1回散 乱光の光強度は

$$
I_{1}(0,-\widehat{\mathbf{k}}: L)=I_{0}(0, \widehat{\mathbf{k}}) \mu_{s} e^{-\mu_{t} L} p(-\widehat{\mathbf{k}}, \widehat{\mathbf{k}})
$$

\section{で表される.}

Fig.2(b)に示す 2 回散乱光の場合は，1 回目または 2 回 目の散乱は, 入射光軸上の深さ $L / 2$ の位置で後方に散乱 される.もう 1 つの散乱は, 入射光軸上の深さ $L / 2$ より 近い位置で前方に散乱される。（4）式を用いると 2 回散 乱光の光強度は

$$
\begin{aligned}
I_{2}(0, & -\widehat{\mathbf{k}}: L) \\
= & I_{0}(0, \widehat{\mathbf{k}})\left(\mu_{s}\right)^{2} e^{-\mu_{t} L}\left[\int_{0}^{L / 2} p(-\widehat{\mathbf{k}}, \widehat{\mathbf{k}}) p(\widehat{\mathbf{k}}, \widehat{\mathbf{k}}) d s\right. \\
& \left.+\int_{0}^{L / 2} p(-\widehat{\mathbf{k}},-\widehat{\mathbf{k}}) p(-\widehat{\mathbf{k}}, \widehat{\mathbf{k}}) d s\right]
\end{aligned}
$$

の積分で表される。］］内の 1 項目は 1 回目が前方散 乱, 2 回目が後方散乱の場合を，2 項目はその逆を表して いる. この被積分関数は定数であり，積分を実行すると， 2 回散乱光の光強度は

$$
I_{2}(0,-\widehat{\mathbf{k}}: L)=I_{0}(0, \widehat{\mathbf{k}})\left(\mu_{s}\right)^{2} L e^{-\mu_{t} L}
$$

となる。

3 回散乱光の散乱点の配置を Fig.2(c)に示す。この場 合, 1 回目と 3 回目の散乱点は入射光軸上の深さ $L / 2$ よ り近い位置である。 また，光路長が $L$ となるためには, 1 回目と 3 回目の散乱点を焦点とし, 入射光軸上の深さ 


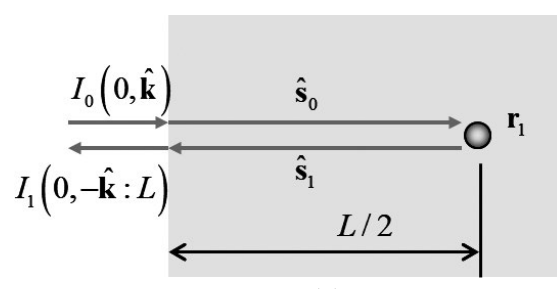

(a)

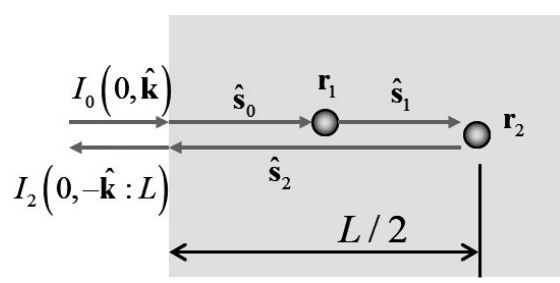

(b)

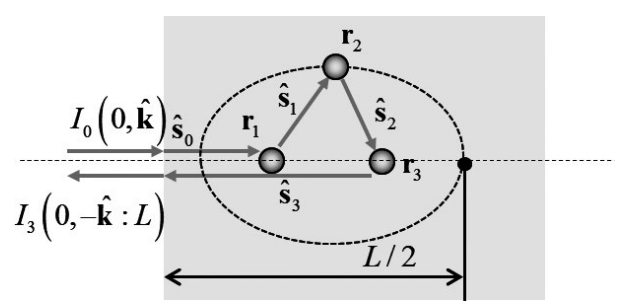

(c)

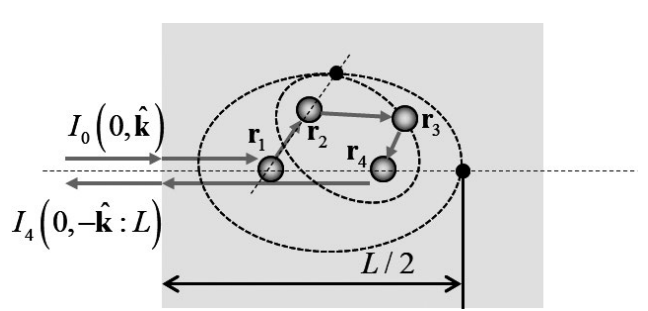

(d)

Fig.2 Configuration of scattering points and scattering processes for (a) single scattering, (b) second-order scattering, (c) third-order scattering, and (d) fourthorder scattering.

$L / 2$ の点を通る回転楕円体を考える. 2 回目の散乱点は， その回転楕円体の表面上でなければならない。したがっ て, 3 回散乱光の光強度は, 1 回目と 3 回目の散乱点の積 分と 1 回目の散乱角の積分を用いて

$$
\begin{aligned}
I_{3}(0,-\widehat{\mathbf{k}}: L) & \\
= & I_{0}(0, \widehat{\mathbf{k}})\left(\mu_{s}\right)^{3} L^{2} e^{-\mu_{t} L} \int_{0}^{1 / 2} \int_{0}^{1 / 2} \int_{4 \pi} p\left(-\widehat{\mathbf{k}}, \widehat{\mathbf{s}}_{2}\right) \\
& \quad p\left(\widehat{\mathbf{s}}_{2}, \widehat{\mathbf{s}}_{1}\right) p\left(\widehat{\mathbf{s}}_{1}, \widehat{\mathbf{k}}\right) d \omega_{1} d \widehat{s}_{1} d \widehat{s}_{3}
\end{aligned}
$$

と表される. ここで, 積分変数の光路長 $\hat{s}_{i}=s_{i} / L$ は全光 路長 $L$ で規格化している. そのため積分範囲は 0 から $1 / 2$ であり，積分の前に $L^{2}$ が掛けられている. また， $\widehat{\mathbf{s}}_{i}$ は $i$ 回散乱光の伝搬方向の単位べクトルである。（9）式をモ ンテカルロ積分で計算すると, 3 回散乱光の光強度が得 られる. このモンテカルロ積分は光路長の長さに無関係 であり，光路長ごとに計算する必要はない，一度この積
分を実行するだけで，3 回散乱光の光路長分布関数が得 られる。

モンテカルロ積分を実行するためには，1 回目と 3 回 目の散乱点，および，1 回目の散乱方向を乱数によって 決定する. 1 回目と 3 回目の散乱点を決定するには，散 乱間の光路長を乱数で発生させる. 規格化された光路長 は 1 であり，3 回散乱光を考えているので，光路長を 3 点で 4 分割すれば, 散乱間に光が直進する光路長を決定 できる.したがって， $[0,1]$ の一様乱数を 3 つ発生させ， その最小值の乱数を選ぶことで，3 回散乱の光路長の発 生確率に合うようにランダムに決定することができる. この乱数の確率密度関数は

$$
g(s)=n(1-s)^{n-1}
$$

で与えられる。ここで， $n$ は散乱回数である。このよう に発生させた乱数が $1 / 2$ より大きい場合は, 再度, 乱数 を発生させる. 1 回目の散乱方向は一様乱数により決定 する. 1 回目と 3 回目の散乱点を焦点とし, 入射光軸上 の深さ $L / 2$ の点を通る回転楕円体の表面と 1 回目の散乱 方向との交点が 2 回目の散乱点である。これで，1 回目 と 2 回目の散乱方向が決定され，（9）式の被積分関数の 值が計算できる。この手順で, 多数の散乱点の組み合わ せを発生させることで，モンテカルロ積分により積分の 值を求める. この方法での散乱点の発生では, 散乱係数, 減光係数，位相関数などの散乱媒質の特性は全く関係し ていない。したがって，一度発生させた散乱点の組み合 わせは，様々な媒質の散乱光強度を計算に利用できる. これはこの計算方法の利点である.

次に, Fig.2(d)に示すような 4 回散乱光の散乱光強度を 説明する. この場合, 1 回目と 4 回目の散乱点は入射光 軸上の深さ $L / 2$ より近い位置である. また, 光路長が $L$ となるためには, 2 回目の散乱点は, 1 回目と 4 回目の散 乱点を焦点とし入射光軸上の深さ $L / 2$ の点を通る回転楕 円体の内側でなければならない. 次に，3回目の散乱点 を考える. 2 回目の散乱点で考えた回転楕円体の表面と 1 回目の散乱方向との交点に 3 回目の散乱点があると光 路長は $L$ となる。 その点を通り，2 回目と 4 回目の散乱 点を焦点とする回転楕円体の表面上に 3 回目の散乱点が あれば，光路長は $L$ となる.したがって，4回散乱光の 光強度は, 1 回目, 2 回目と 4 回目の散乱点の積分と 1 回 目と 2 回目の散乱角の積分を用いて,

$$
\begin{aligned}
I_{4}(0,-\widehat{\mathbf{k}}: L)=A_{4} I_{0}(0, \widehat{\mathbf{k}})\left(\mu_{s}\right)^{4} L^{3} e^{-\mu_{t} L} \\
A_{4}=\int_{0}^{1 / 2} \int_{0}^{s^{\prime}{ }_{2} \max } \int_{0}^{1 / 2} \int_{4 \pi} \int_{4 \pi} p\left(-\widehat{\mathbf{k}}, \widehat{\mathbf{s}}_{3}\right) \\
\quad p\left(\widehat{\mathbf{s}}_{3}, \widehat{\mathbf{s}}_{2}\right) p\left(\widehat{\mathbf{s}}_{2}, \widehat{\mathbf{s}}_{1}\right) p\left(\widehat{\mathbf{s}}_{1}, \widehat{\mathbf{k}}\right) d \omega_{1} d \omega_{2} d \widehat{s}_{1} d \widehat{s}_{2} d \widehat{s}_{4}
\end{aligned}
$$

と表される。（12）式の積分をモンテカルロ積分で計算す るには，次の手順で散乱点を発生させればよい。はじめ に，(10）式の確率密度関数を持つ乱数により 1 回目と 4 回目の散乱点を発生，次に，一様乱数で 1 回目の散乱方 向を決定し, その散乱方向と（10）式の確率密度関数を 
持つ乱数により 2 回目の散乱点を決定, 最後に一様乱数 で 2 回目の散乱方向と 3 回目の散乱点を決定する. 2 回 目の散乱点の決定の時に, 散乱点が回転楕円体の外に なった場合には，光路長を決めな打す． $n$ 回散乱光の光強度は

$$
\begin{aligned}
I_{n}(0,-\widehat{\mathbf{k}}: L)=A_{n} I_{0}(0, \widehat{\mathbf{k}})\left(\mu_{s}\right)^{n} L^{n-1} e^{-\mu_{t} L} \\
A_{n}=\int_{\widehat{s}_{1}} \cdots \int_{\widehat{s}_{n}} \int_{\omega_{1}} \cdots \int_{\omega_{n-2}} \prod_{j=1}^{n} p\left(\widehat{\mathbf{s}}_{j}, \widehat{\mathbf{s}}_{j-1}\right) d \omega_{1} \\
\quad \cdots d \omega_{n-2} d \widehat{s}_{1} \cdots d \widehat{s}_{n}
\end{aligned}
$$

で表される。これまでと同様の手順で，散乱点の組み合 わせを発生させ，モンテカルロ積分により（14）が計算 できる. 散乱回数の増加とともに積分が増えるため，モ ンテカルロ積分の精度は低下する．精度を高めるために は，より多くの散乱点の組み合わせを発生させる必要が あり，計算時間が増加していく。

\section{4. 均一な散乱媒質の光伝搬解析}

散乱特性が均一な散乱媒質に対する, 特定の光路長の 伝搬経路のみを発生させるモンテカルロ法を用いた解析 結果を示す. Fig.3 は, 1 回散乱光から 30 回散乱光まで の散乱光強度, および, それらの総和である全散乱光強 度の光路長依存性を示す。これらの強度は入射光と同じ 点から垂直に出射する散乱光の光強度である. 横軸は平 均自由行程 $l$ で規格化した光路長, 縦軸は, 光路長 0 で の全散乱光強度で規格化した光強度である.ここで，平 均自由行程は, 散乱されずに光が直進する平均的な距離 であり，減光係数の逆数である．散乱体は水中に懸濁す る直径 $100 \mathrm{~nm}$ のポリスチレン球, 入射光の真空中の波 長は $810 \mathrm{~nm}$ を仮定している. この時の散乱体の相対屈 折率は 1.20 である.これらの条件をもとにミ一散乱の位 相関数を求め, モンテカルロ積分に用いている. この時 の非等方性パラメータは 0.046 である. 各散乱回数につ き，1,000,000 組の散乱点分布を発生させ，モンテカルロ 積分を実行している. 1 回散乱光の光強度は光路長が 0 のとき 1 であり, 光路長の増加とともに指数関数的に減 衰する. 2 回以上の散乱光の光強度は, 光路長が 0 のと きは 0 であり, 光路長の増加とともに増加し, 散乱回数 と平均自由行程の光路長あたりで最大となり, その後減 少していく. 全散乱光強度は, 光路長が平均自由行程よ り長くなると，多重散乱光の影響により徐々に指数関数 的な減衰から外れていく.また，この結果から特定の光 路長を伝搬した散乱光の散乱回数分布も求めることがで きる。その結果，30 回散乱光までの計算では，平均自由 行程の 20 倍程度の光路長まで正確に計算できている.

Fig.4 は，モンテカルロ積分で発生された光路長が 1 の ときの散乱点の分布を積算した結果を示している. 各散 乱点には，(14）式の被積分関数である位相関数の積の值 が重みとして掛けられている. これらの図は入射光の光 軸を含む断面での散乱点分布であり，領域の大きさは 1 $\times 1$ である. 入射光は図の左側の中心から垂直に入射さ

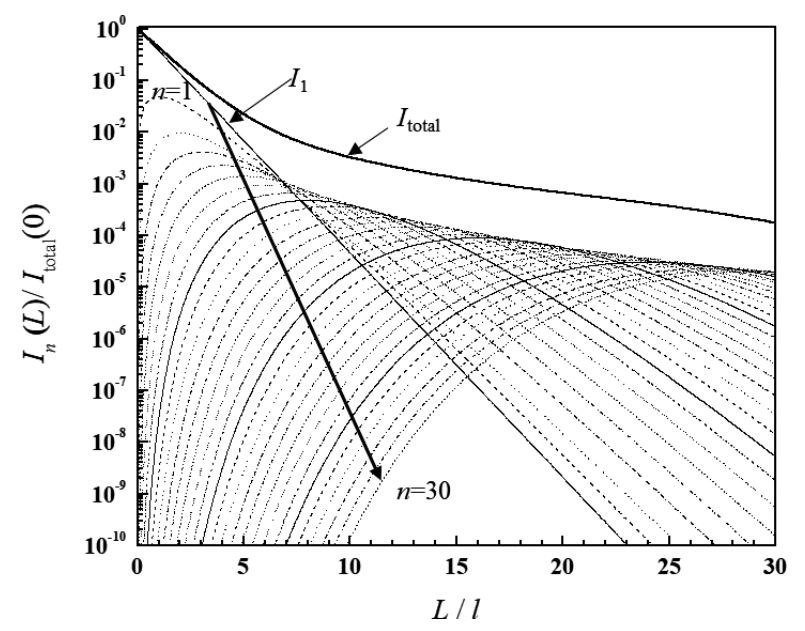

Fig.3 Path-length dependence of scattered light intensity of single scattered light to $30^{\text {th }}$ order scattered and total scattered light on path length. They are calculated using path-length-assigned Monte Carlo simulation.

れている.この散乱点分布は，すべての散乱光の広がり を示しているのではなく, 入射光と同じ位置から垂直に 出射する散乱光が散乱される位置の分布を示しているこ とに注意されたい. 3 章で説明したとおり， 1 回散乱光の 散乱点は図中心の深さ $1 / 2$ の一点であり, 2 回散乱光の 散乱点は，入射点から中心までの光軸上に分布する。 3 回散乱光以上では，光軸上以外にも散乱点の分布が広 がっている. 散乱回数の増加とともに, 光軸から遠い位 置まで散乱点が広がり, より浅い位置の散乱点が増加し ていく。また 6 回散乱程度までは，光軸上の近くの散乱 点が多いことがわる．この程度の散乱回数までは，準直 進光の成分が多く残っていることを示している。 また， 散乱回数が 15 回程度を超えると, 散乱点は入射点の近く に等方的に広く分布するようになる。これは，散乱光が 拡散的になっていることを示している.

Fig.5 は，光路長が変化したときの入射点と同じ位置か ら垂直に出射する全散乱光の散乱点分布の変化を示して いる. 図の縦と横の大きさは散乱光の光路長となってい るので, 散乱光の広がりは同じに見えるが, 光路長の増 加とともに散乱光は深い位置まで伝搬している. 光路長 が平均自由行程と等しい散乱光では， $88 \%$ が深さ $L / 2$ の 点で散乱される 1 回散乱光である. 光路長が平均自由行 程の 3 倍の散乱光では $60 \% ， 5$ 倍の散乱光では $30 \%, 10$ 倍の散乱光では $1 \%$ 程度と 1 回散乱光の割合は，光路長 の増加とともに減少していく，それにともなって，散乱 点の分布は光軸から遠い点まで広がり, 浅い位置の散乱 点が増加していく，それらの散乱点の分布から散乱点の 重心位置を求めると, 光路長が平均自由行程程度までは, 光路長の増加に比例して散乱点の深さが増加する.この 領域では直進成分の散乱光が検出可能である. 光路長が 平均自由行程程度の 5 倍程度までは, 増加率は減少する が光路長の増加とともに散乱点の平均深さが増加してい く.この領域では, 準弾性散乱光の検出が可能である. 光路長が平均自由行程程度の 5 倍を超えると散乱点の平 


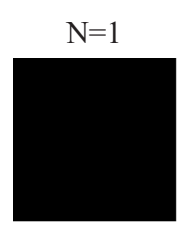

$\mathrm{N}=7$

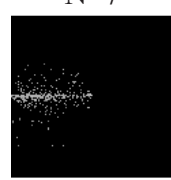

$\mathrm{N}=13$

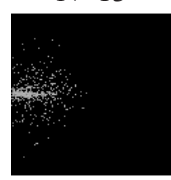

$\mathrm{N}=19$

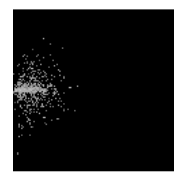

$\mathrm{N}=25$

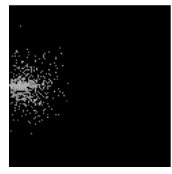

$\mathrm{N}=2$

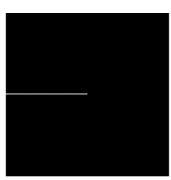

$\mathrm{N}=8$

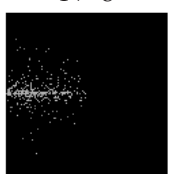

$\mathrm{N}=14$

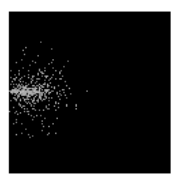

$\mathrm{N}=20$

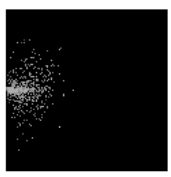

$\mathrm{N}=26$

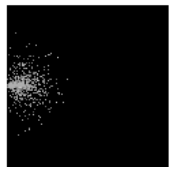

$\mathrm{N}=3$

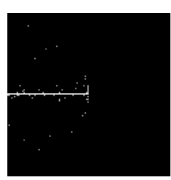

$\mathrm{N}=9$

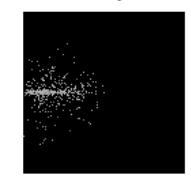

$\mathrm{N}=15$

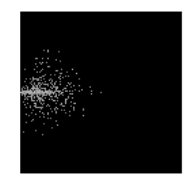

$\mathrm{N}=21$

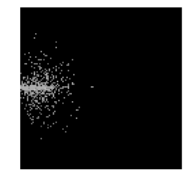

$\mathrm{N}=27$

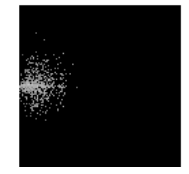

$\mathrm{N}=4$

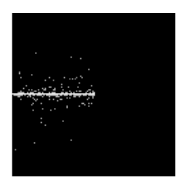

$\mathrm{N}=10$

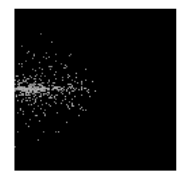

$\mathrm{N}=16$

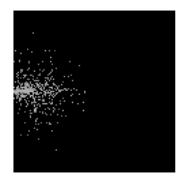

$\mathrm{N}=22$

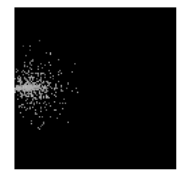

$\mathrm{N}=28$

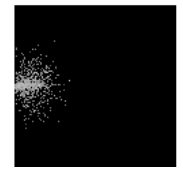

$\mathrm{N}=5$

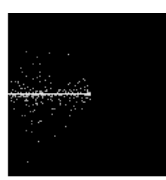

$\mathrm{N}=11$

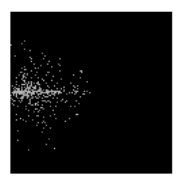

$\mathrm{N}=17$

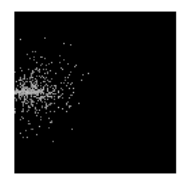

$\mathrm{N}=23$

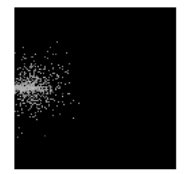

$\mathrm{N}=29$

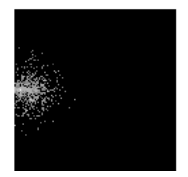

$\mathrm{N}=6$

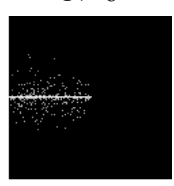

$\mathrm{N}=12$

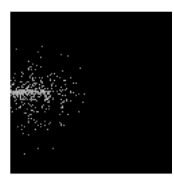

$\mathrm{N}=18$

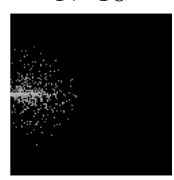

$\mathrm{N}=24$

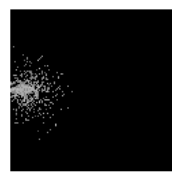

$\mathrm{N}=30$

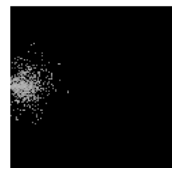

Fig.4 Scattering points distributions of scattered light from single scattered light to $30^{\text {th }}$ order scattered, which is obtained from path-length-assigned Monte Carlo simulation.
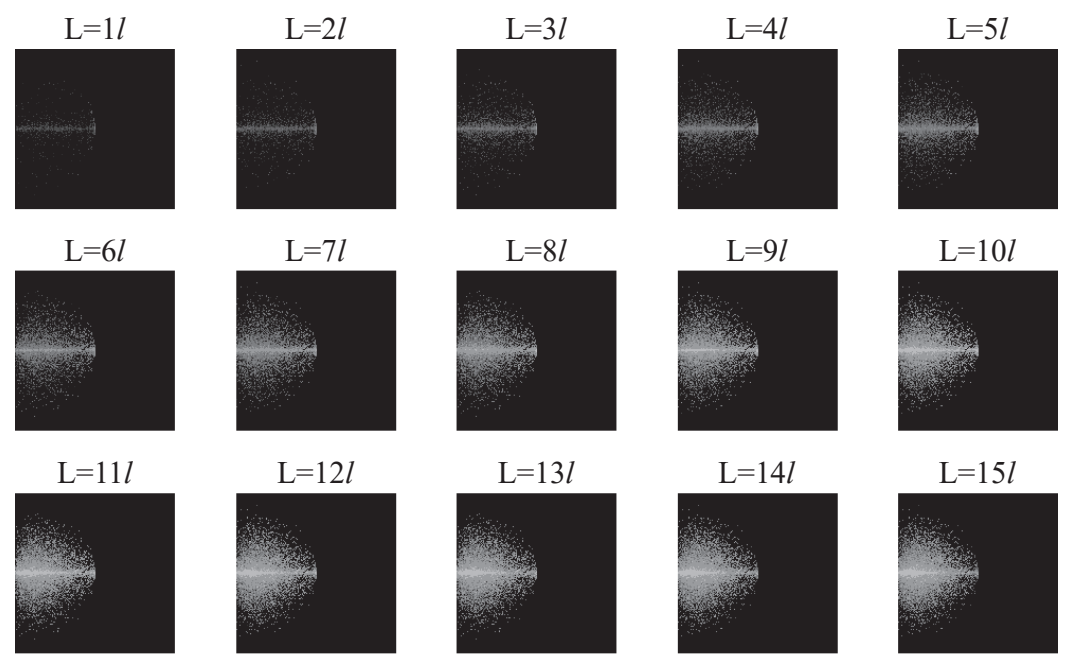

\section{$\mathrm{L}=13 l$}
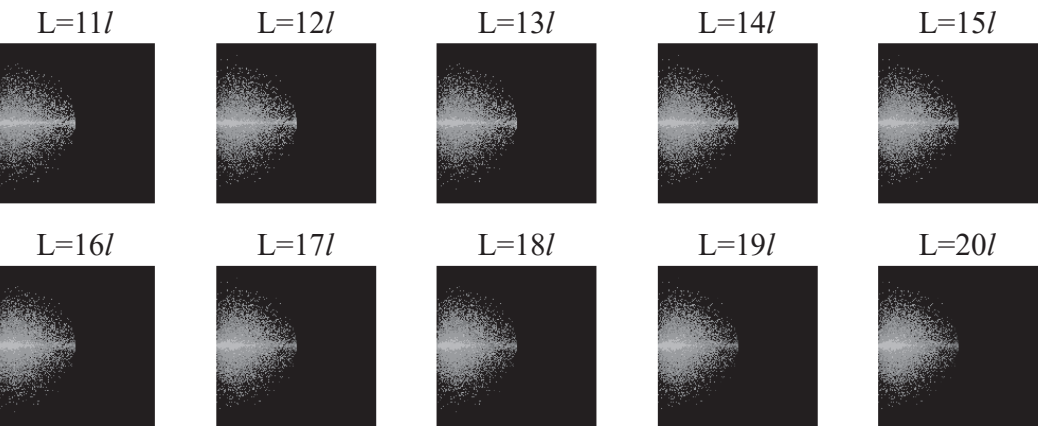

Fig.5 Scattering points distributions of scattered light in cases of path length from $L=l$ to $L=20 l$. They are calculated using pathlength-assigned Monte Carlo simulation. 
均深さは, 平均自由行程程度の 1.5 倍で変化しなくなる. これはその位置を中心にして，光が拡散的に広がってい ることを意味している。平均深さが変化しないことは, 光路長が増加してもそれ以上深い位置まで光が到達しな いわけではない. 散乱点分布の光軸方向の幅 (標準偏差) は, 光路長の増加とともに増加しつづける。 また, 光軸 方向に垂直な方向の散乱点分布の幅は, 光路長が平均自 由行程程度の 5 倍程度まではほぼ 0 である。 それより長 い光路長では, 垂直方向の幅も徐々に増加していくが, 光軸方向の幅に比べると $1 / 10$ 以下と狭い. これは, 媒質 に垂直に光を入射し, 入射点から垂直に出射する散乱光 を検出する光学配置では, 多重散乱の影響が強くなった 場合でも光軸上の情報を取得できることを示している.

本章では，特定の光路長の伝搬経路のみを発生させる モンテカルロ法を用いた均一な散乱体に対する媒質解析 結果を示した. この解析方法は, 媒質に垂直に光を入射 し, 入射点から垂直に出射する散乱光のみ発生させるた め, このような光学配置での散乱光の解析を, 従来の方 法より効率的に行うことができる，この方法では，散乱 回数ごとに解析を行っていくため, 考慮する散乱回数が 増加すると計算時間が増加していく．また，散乱回数が 増加すると計算精度も低下する. しかし, 直進光, 準直 進光, 拡散的になり始める散乱光の領域の解析では, 効 率的に解析ができる. また，この方法での散乱点分布の 発生では, 媒質の特性に関係する散乱係数, 吸収係数, および，位相関数を全く使用しない.したがって，一度 発生させた散乱点の分布は異なる散乱特性の媒質にも利 用でき, 様々な媒質の繰返しの解析はより効率的である.

\section{5. 散乱特性に空間分布がある場合の光伝搬解析}

本章では, 散乱係数, 減光係数, 位相関数が不均一で ある散乱媒質に対する散乱光の解析に, 特定の光路長の 伝搬経路のみを発生させるモンテカルロ法を適用する方 法とその解析例を示す.

散乱係数, 減光係数, 位相関数が位置の関数である場 合，（13）と（14）式で表された $n$ 回散乱光の光強度は,

$$
\begin{gathered}
I_{n}(0,-\widehat{\mathbf{k}}: L)=A_{n} I_{0}(0, \widehat{\mathbf{k}}) L^{n-1} \\
A_{n}=\int_{\widehat{s}_{1}} \cdots \int_{\widehat{s}_{n}} \int_{\omega_{1}} \cdots \int_{\omega_{n-2}} \prod_{j=1}^{n} \mu_{s}\left(\mathbf{r}_{j}\right) \\
p\left(\widehat{\mathbf{s}}_{j}, \widehat{\mathbf{s}}_{j-1}, \mathbf{r}_{j}\right) \exp \left[-\int \mu_{t}\left(\mathbf{r}_{j}\right) d s\right] \\
d \omega_{1} \cdots d \omega_{n-2} d \hat{s}_{1} \cdots d \widehat{s}_{n}
\end{gathered}
$$

となり，散乱係数と減光係数に関係する項が積分の中に 残る。（16）式の積分をモンテカルロ積分で評価すれば, 不均一媒質の解析ができる. この時, 指数関数の中の積 分もモンテカルロ積分で評価する. モンテカルロ積分の 評価に必要な散乱点分布の発生は，4 章で説明した均一 媒質の場合と同じものを使うことができる。これは，散 乱点発生の方法が散乱体の特性に依存しないためである. 散乱特性に分布がある場合には，(16）式の被積分関数は
位置の関数であるため，光路長ごとにモンテカルロ積分 を行う必要がある. また, 指数関数の中の積分には, 散 乱点の位置でなく, 散乱光の経路が必要となる. 我々ば, 次の手順でモンテカルロ積分を計算する.

（1）散乱係数, 減光係数, 位相関数を 3 次元のボクセ ルデータとして定義する.

(2) 3 章で説明した方法で散乱回数ごとの散乱点分布 を発生させる. 光路長は 1 である。

(3) 光路長ごとの散乱点分布を計算する.

(1)（2）で発生させた散乱点の座標に光路長を掛ける.

(2)散乱点が含まれるボクセルを決定する.

(3)散乱光の経路を求め, ボクセル内を光が横切る長さ を記録したボクセルデータを作成する.

（4）モンテカルロ積分を実行する.

(1)散乱点が含まれるボクセルに対応する散乱係数と位 相関数の積を計算する.

(2)光路長のボクセルデータと減光係数のボクセルデー タの対応するボクセル同士の積を求め, それらの総和を 計算する.

（2）の計算は，一度実行すれば繰り返し使用すること ができる。（3）の計算も光路長ごとに一度計算すればよ い. 光路長の分解能はボクセルの分解能とは独立に決定 できる.（3）のデータは計算したい光路長ごとに保存し ておく必要があり，大きな保存領域が必要となる．この 2 つの計算は一度実行すればよいが, 多数の散乱点分布 を発生させ，それを光路長ごとの散乱点と光路長のデー タに変換するには長い計算時間が必要になる。しかし， 媒質の特性と空間分布を変化させて繰り返し計算を行う 場合には，(4) の計算のみとなり効率的に計算ができる.

Fig.6 に示すような散乱媒質からの散乱光の光路長分布 を計算した結果を示す。散乱媒質表面には, 濃い灰色で 示される散乱の強い層があり, 内部にも同じ散乱の強さ の直方体の領域が存在している. それ以外の薄い死色で

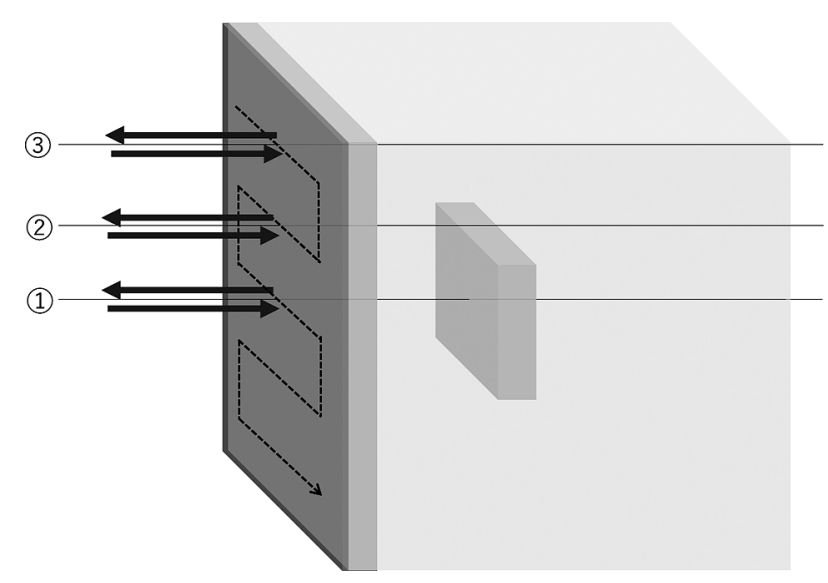

Fig.6 Illustration of the assumed model of scattering medium. Light is incident from left side. The surface layer shown in dark gray has scattering coefficient 100 times stronger than surroundings shown in light gray. Rectangular region shown in dark gray embedded in the scattering medium also has scattering coefficient 100 times stronger than surroundings. 
示される領域の散乱係数は $1 / 100$ であり，吸収係数はと もに 0 である. 領域は $100 \times 100 \times 100$ である. 位相関数 は 4 章と同じものを使用した。罒の太い矢印で示すよう に，光は媒質の左側から垂直に入射され，同じ位置から 垂直に出射する散乱光の光路長分布を計算する. 光の入 射・出射位置を四の点線で示すように変化させながら繰 り返し光路長分布を計算した. Fig.7 は，光の入射・検出 位置が媒質の中心の場合の 1 から 9 回散乱光と全散乱光 の光強度を示している. 灰色で塗りつぶされた領域は, 散乱が強い場所に対応する光路長の領域を示している. 1 回散乱光では, 散乱の強い位置に対応した光路長で散 乱光が強くなっている. 多重散乱光では, 少し長い光路 長の散乱光が強くなっており, そのずれは, 散乱回数が 増えるにしたがって増加する。 これは多重散乱光が散乱 体内部を蛇行しながら進むためである。全散乱光では, 散乱の強い位置に対応した光路長の散乱光が強いが，そ の長光路側に少し強い散乱が現れる. Fig.8 は，Fig.6中 に(1)で示すように光軸が散乱媒質の中心の場合の光路長 分布と, (2)で示すような光軸が内部の散乱体のわずかに 外側の場合の光路長分布, (3)で示すような光軸が内部の 散乱体から遠い場合の光路長分布を示す.さらに, 入射・ 出射位置を変化させたときの光路長 $0.7,4.3,6.7,12.7$ の散乱光の強度分布を示す。それぞれの散乱光分布は, 表面の強い散乱領域, 表面の下の弱い散乱領域, 内部の 強い散乱領域, 内部の散乱領域より深い位置に対応して
いる.内部の散乱体のわずかに外側から光を入射した場 合には，内部の散乱体の影響により，対応する光路長の

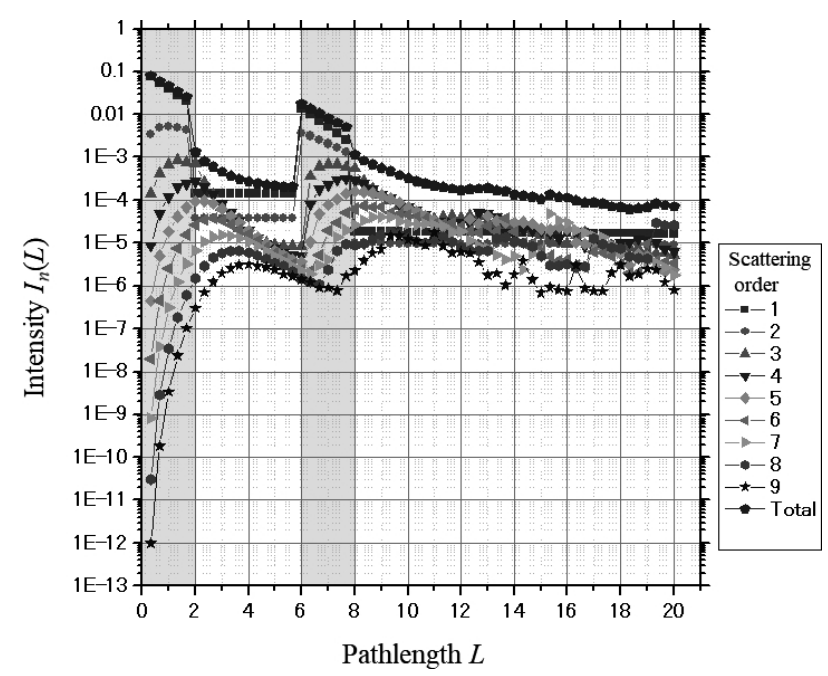

Fig.7 Path-length dependence of scattered light intensity from single scattered light to $9^{\text {th }}$ order scattered and total scattered light for the scattering medium shown in Fig.6. The incident point of light is the center of the medium. Gray regions express the pathlength corresponding to strong scattering layer.

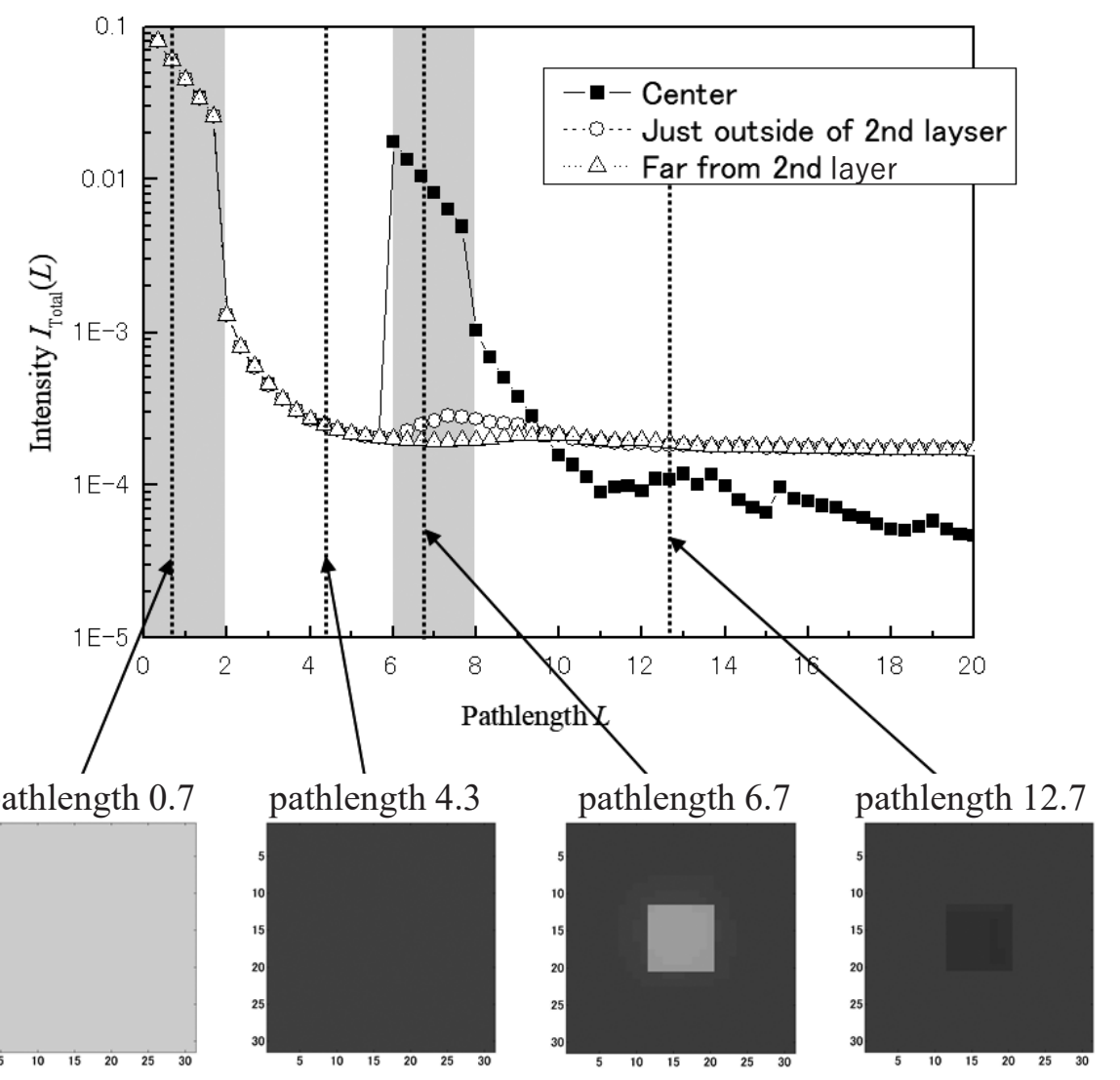

Fig.8 Path-length dependence of scattered light intensity in the case that (1) the incident point of light is the center of the medium, (2) just outside of the second layer and (3) far from the second layer. Lower figures show the dependence of the intensity of scattered light of scattered light with the path-length of $0.7,4.3,6.7$, on the incident point. 
散乱光がわずかに増加していることがわかる.内部の散 乱体から遠い場所に光を入射したときは, 内部の散乱体 の影響はほとんど見られない。また，光路長 6.7 の散乱 光の分布では, 内部の散乱体に対応した位置の散乱光が 強くなっており，その外側もわずかに散乱光が強くなっ ていることが確認できる。 より長い光路長では, 内部の 散乱体により光が強く散乱されたため, 対応する散乱光 が弱くなっている.

本計算方法を用いると，光干渉断層撮影法で計測され る散乱光を，多重散乱光を含めてシミュレーションする ことが可能である.

\section{6. まとめ}

本解説では, 光干渉断層撮影法などの計測などで行わ れる，媒質に垂直に光が入射し同じ位置から垂直に出射 する多重散乱光を効率的に解析するモンテカルロ法につ いて解説した。 このような特定の散乱光のみを解析する 場合, 通常のモンテカルロ法は散乱光の光路長と出射位 置はランダムに決定するので, 計算効率が悪い. 紹介し た方法は，対象の散乱光のみをランダムに発生できるの で，効率的に散乱光の光路長分布が計算できる. 散乱特 性が均一な媒質に対しては，非常に少ない計算量で解析 が可能である. 散乱特性に空間分布がある媒質では，計 算量とデータ量が増加するが，媒質を変化させながらの 繰返し計算は効率的である。

\section{利益相反の開示}

利益相反なし.

\section{引用文献}

1) Vo-Dinh T. (ed.) Biomedical photonics handbook: Fundamentals, Devices, and Techniques. CRC Press; 2014.

2) Vo-Dinh T. (ed.) Biomedical photonics handbook: Biomedical Diagnostics. CRC Press; 2014.

3) Yodh A, Britton C. Spectroscopy and imaging with diffusing light. Phys Today. 1995; 48: 34-40.

4) 山下優一, 牧敦, 小泉英明. 光トポグラフィによる脳 機能の無侵襲画像化. 化学と工業. 1996; 49: 1562-1564.

5) Culver JP, Choe R, Holboke MJ, Zubkov L, Durduran T, Slemp A, Ntziachristos V, Chance B, Yodh A. Threedimensional diffuse optical tomography in the parallel plane transmission geometry: Evaluation of a hybrid frequency domain/continuous wave clinical system for breast imaging. Med Phys. 2003; 30: 235-247.

6) Maki A, Yamashita Y, Ito Y, Watanabe E, Mayanagi Y, Koizumi H. Spatial and temporal analysis of human motor activity using noninvasive NIR topography. Med Phys. 1995; 22: 1997-2205.

7) Huang D, Swanson EA, Lin CP, Schuman JS, Stinson WG, Chang W, Hee MR, Flotte T, Gregory K, Puliafito CA, Fujimoto JG. Optical coherence tomography. Science. 1991; 254: 1178-1181.

8) 安野嘉晃. 眼科における光干渉断層イメージングのトレ ンド. 光学. 2014; 43: 538-542.

9) Ishimaru A. Wave propagation and scattering on random media; IEEE Press; 1999.

10) 清水孝一. 生体組織における光伝搬の解析. 光学. 2012;
41: 414-423.

11) Wang L, Jacques SL, Zheng L. MCML - Monte Carlo modeling of light transport in multi-layered tissues. Compt Methdos Programs Biomed. 1995; 47: 131-146.

12) Ishii $K$, Iwai $T$, Nakamura $S$. Numerical analysis of a pathlength-resolved spectrum of time-varying scattered light field. J Opt Soc Am A. 2008; 25: 718-724.

13) Ishii K, Nishidate I, Iwai T. Analysis of light propagation in highly scattering media by path-length-assigned Monte Carlo simulations. Opt Rev. 2014; 21: 210-214.

14) 岡田達弘, 西舘泉, 石井勝弘, 岩井俊昭. 光断層計測 のモンテカルロシミュレーションに打ける空間分解能の 検討. 第 50 回光波センシング技術研究会講演論文集. 2012; 50: 237-243.

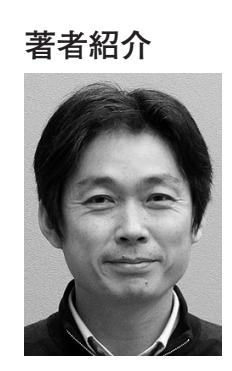

石井 勝弘 (Katsuhiro Ishii)

1998 年 9 月北海道大学大学院工学研究 科電子情報工学専攻後期博士課程修了 (博士 (工学) )。1998 年 10 月北海道大 学大学電子科学研究所助手, 2005 年 4 月光産業創成大学院大学光産業創成研 究科助教授, 2007 年 4 月同准教授, 2018年 4 月同教授. 応用光学, 光計測, 光散乱. 応用物 理学会. 応用物理学会, 日本光学会, レーザー学会, 日 本物理学会. 応用物理学会講演奨励賞 (1997 年), 日本 光学会奨励賞 (1998 年), 光学設計奨励賞 (2011 年). 